\title{
Cytocompatibility and Uptake of Halloysite Clay Nanotubes
}

\author{
Viviana Vergaro, ${ }^{\dagger}$ Elshad Abdullayev, ${ }^{\ddagger}$ Yuri M. Lvov, ${ }^{\ddagger}$ Andre Zeitoun, ${ }^{\S}$ Roberto Cingolani, ${ }^{\dagger}$ \\ Ross Rinaldi, ${ }^{\dagger}$ and Stefano Leporatti ${ }^{*}{ }^{\dagger}$ \\ National Nanotechnology Laboratory (NNL) of CNR-INFM, Italian Institute of Technology (IIT) Lecce Unit, \\ University of Salento, ISUFI Lecce, 73100 Italy, Institute for Micromanufacturing and Biomedical \\ Engineering Program, Louisiana Tech University, 911 Hergot Avenue, Ruston, Louisiana 71272, and \\ Applied Minerals, Inc., New York, New York
}

Received December 19, 2009; Revised Manuscript Received January 29, 2010

\begin{abstract}
Halloysite is aluminosilicate clay with hollow tubular structure of $50 \mathrm{~nm}$ external diameter and $15 \mathrm{~nm}$ diameter lumen. Halloysite biocompatibility study is important for its potential applications in polymer composites, bone implants, controlled drug delivery, and for protective coating (e.g., anticorrosion or antimolding). Halloysite nanotubes were added to different cell cultures for toxicity tests. Its fluorescence functionalization by aminopropyltriethosilane (APTES) and with fluorescently labeled polyelectrolyte layers allowed following halloysite uptake by the cells with confocal laser scanning microscopy (CLSM). Quantitative Trypan blue and MTT measurements performed with two neoplastic cell lines model systems as a function of the nanotubes concentration and incubation time indicate that halloysite exhibits a high level of biocompatibility and very low cytotoxicity, rendering it a good candidate for household materials and medicine. A combination of transmission electron microscopy (TEM), scanning electron microscopy (SEM), and scanning force microscopy (SFM) imaging techniques have been employed to elucidate the structure of halloysite nanotubes.
\end{abstract}

\section{Introduction}

Halloysite clay is a two-layered aluminosilicate, chemically similar to kaolin, which has hollow tubular structure in the submicrometer range. ${ }^{1-3}$ Kaolin sheets are rolled into tubes because of the strain caused by lattice mismatch between adjacent silicone dioxide and aluminum oxide layers. ${ }^{1,2}$ As for most natural materials, the size of halloysite particles varies from 50 to $70 \mathrm{~nm}$ in external diameter, ca. $15 \mathrm{~nm}$ diameter lumen and $1 \pm 0.5 \mu \mathrm{m}$ length. Halloysite nanotubes (HNTs) are capable of entrapping a range of active agents within the inner lumen, followed by their retention and slow release. ${ }^{3-13}$

There is an increasing amount of research ongoing to produce functional nanometer-scale containers, and there is growing demand for their use in biomedical applications. Such containers would be inexpensive materials with a simple means of fabrication, and thus natural resources and nanotubes are good candidates for this. Different chemistry of the inner and outer surfaces in halloysite tubes would also allow for separate modification of inner and outer walls, for example, for selective labeling. The lumen diameter of halloysite tube fits well to macromolecule and protein diameters, allowing their encasing in the tube. Halloysite is a natural product which will not add risk to the environment.

Halloysite was found to be a viable and inexpensive nanoscale container for encapsulation of drugs that was first demonstrated by Price, Lvov, and Kelly, et al. ${ }^{3-5}$ Polymer-halloysite composites are perspective materials for medical implants, for example, for bone repairing. ${ }^{5,14-16}$ Biocompatibility is one of

* To whom correspondence should be addressed. E-mail: stefano.leporatti@ unisalento.it.

¿ University of Salento.

Louisiana Tech University.

$\S$ Applied Minerals, Inc. the main prerequisites for safe usage of halloysite in the delivery of biologically active substances in medical and household products.

However, a comprehensive study of halloysite biocompatibility has not been done yet. Are there health risks associated with halloysite? Currently, there is no research on cytotoxicity caused by cellular exposure to halloysite in concentrations viable for commercial applications. HNTs are rolled versions of kaolin, and they are just as chemically stable as widely used in household products kaolin clay. However, concern over the use of fine particles rich in silica is understandable. Many diseases, such as fibrosing collagenous pneumoconiosis and silicosis, are related to prolonged lung exposure to fine crystalline silica particles. Studies associate pathogenesis of these diseases to (1) generation of free radicals by the particles and (2) overactive inflammatory response by intra-alveolar/interstitial macrophages.

In this article, we focused on studying HNTs interaction (both untreated and fluorescently labeled) with cells. We analyzed halloysite toxicity and visualized the process of cell uptake of fluorescently labeled clay nanotubes with confocal laser scanning microscopy (CLSM). Intracellular uptake by cells of different origins (cervical adenocarcinoma, HeLa, or breast cancer cells, MCF-7) and cytoviability tests (MTT and Trypan blue) demonstrated halloysite cytocompatibility and potential as biofriendly cargo nanocontainer for biomaterials.

\section{Materials and Methods}

Chemicals. The sources of the chemicals are as follows: poly (sodium 4-styrene-sulfonate) (PSS, Sigma), poly (allylamine hydrochloride) (PAH, Sigma), fetal bovine serum (FBS, Sigma), penicillinstreptomycin solution (Sigma), sodium pyruvate (Sigma), DMEM medium (Sigma), thiazolyl blue tetrazolium bromide $>97.5 \%$ TLC (Sigma), phosphate-buffered saline, Dulbecco A (PBS, Oxoid), sephadex G25 (Sigma), fluorescein isothiocyanate isomer I (FITC, Aldrich), triton X-100 (Sigma), aminopropyltriethoxysilane (APTES, 99\%, 
Aldrich). Purified dehydrated HNTs were obtained from Applied Minerals, Inc.

Halloysite Labeling. Halloysite Fluorescence Staining by Aminopropyltriethoxysilane Functionalization. We labeled HNTs by modifying their surface with aminopropyltriethoxysilane (APTES). Modified halloysite samples were prepared according to the procedure generally applied for the grafting of silica-based materials. ${ }^{15}$ APTES $(500 \mu \mathrm{L})$ was dissolved in $6.25 \mathrm{~mL}$ of toluene; $0.15 \mathrm{~g}$ of clay powder was added, and the suspension was dispersed ultrasonically for $30 \mathrm{~min}$. The suspension was then refluxed at $120^{\circ} \mathrm{C}$ for $20 \mathrm{~h}$ under constant stirring. The resultant mixture was extensively washed with fresh toluene six times to remove the excess organosilane and then dried overnight at $120{ }^{\circ} \mathrm{C}$ for further curing. The mixture was then washed 10 times with DI water, and the sample was freeze-dried overnight. The amino functionalized nanotubes (HNTs, $3 \mathrm{mg}$ ) were dispersed in $1.5 \mathrm{~mL}$ of $0.1 \mathrm{M}$ carbonate buffer ( $\mathrm{pH}$ 8.0). To this solution $100 \mu \mathrm{L}$ of $13 \mathrm{mM}$ solution of FITC in DMSO was added. The mixture was allowed to react for 2 days under constant stirring at room temperature and protection from light. The solution was dialyzed and lyophilized overnight.

Layer-by-Layer Coating. HNTs were coated using a layer-by-layer $(\mathrm{LbL})$ technique via alternate adsorption of polycations and polyanion. ${ }^{17-19}$ HNTs are negatively charged in water with a $\zeta$ potential of $-40 \mathrm{mV}$ at $\mathrm{pH}$ 6.5. Halloysite dispersed in DI water $(1 \mathrm{~mL})$ was mixed with a solution containing $2 \mathrm{mg} / \mathrm{mL}$ of positively charged poly(allylamine hydrochloride) (PAH). The dispersion was continuously shaken for 10 min. The excess polycation was removed by three centrifugation/ washing steps with DI water. Thereafter, $1 \mathrm{~mL}$ of a $0.5 \mathrm{M} \mathrm{NaCl}$ solution containing $3 \mathrm{mg} / \mathrm{mL}$ of negatively charged poly(sodium 4-styrenesulfonate) (PSS) was added, and the dispersion was continuously shaken for $10 \mathrm{~min}$, followed by three centrifugation/washing steps. This procedure was repeated three times, resulting in the deposition of five polyelectrolyte layers. FITC-labeled PAH layer was inserted into the multilayer to follow HNTs uptake by cells. To prepare PAH-FITC, two solutions (PAH and FITC) were mixed at a ratio of 1:5 (PAH/ FITC), incubated over 2 to 3 days, and then dialyzed against water for 1 to $2 \mathrm{~h}$, followed by drying in lyophilizator and dissolving in water. Finally, free FITC was removed with a Sephadex G25 column in ammoniac buffer $(\mathrm{pH} 8.5)$, dried within lyophilizator, and stored at $+4{ }^{\circ} \mathrm{C}$ before being used in LbL assembly. The final architecture of the fluorescent LbL coating for halloysite was PAH/PSS/PAH-FITC/ PSS/PAH-FITC.

Cell Culture. Human epithelial adenocarcinoma cell line (HeLa) and human breast cancer cell line (MCF-7) were maintained in DMEM medium supplemented with FBS $(10 \%)$, penicillin $(100 \mathrm{U} / \mathrm{mL}$ culture medium), streptomycin (100 $\mu \mathrm{g} / \mathrm{mL}$ culture medium), glutamine (5\%), and sodium pyruvate $(5 \%)$. Cells were grown in a humidified incubator at $37{ }^{\circ} \mathrm{C}, 5 \% \mathrm{CO}_{2}$, and $95 \%$ relative humidity.

Halloysite $\xi$-Potential Characterization. Halloysite surface potential was analyzed by using microelectrophoresis (ZetaPlus Potential Analyzer, Brookhaven Instruments). For this purpose, diluted aqueous dispersion of halloysite (ca. $1 \mu \mathrm{g} / \mathrm{mL}$ ) was transferred into the special cuvette, and electric field was applied across the suspension, causing the movement of negatively charged halloysite nanoparticles toward cathode. Surface electrical potential of the particles was determined by Smoluchowski formula using particle speed measured with dynamic light scattering (all included in the instrument software). To change the $\mathrm{pH}$ of the solution, $\mathrm{HCl}$ or $\mathrm{NaOH}$ were added to the suspensions. A similar procedure was applied for silica and alumina colloids.

Microscopy Imaging. Transmission Electron Microscopy (TEM). TEM images were recorded with a Jeol Jem 1011 microscope operated at an accelerating voltage of $100 \mathrm{kV}$. We prepared samples for analysis by dropping a dilute nanotube dispersion in water onto carbon-coated copper grids and then allowing water to evaporate.

Scanning Electron Microscopy (SEM). Nanotube external surface morphology was characterized by a scanning electron microscope type Hitachi S 4800 FE-SEM; the tube samples were coated with $1 \mathrm{~nm} \mathrm{Pt}$.
Scanning Force Microscopy (SFM). SFM micrographs were obtained with Bioscope II and Multimode-Picoforce (Veeco Instruments Inc.) in air at room temperature using contact mode with MLCT-AUNM cantilevers of $0.01 \mathrm{~N} / \mathrm{m}$ spring constant and in tapping mode using TESPA cantilevers of $4 \mathrm{~N} / \mathrm{m}$ spring constant. A drop of sample suspension was applied to a freshly cleaved mica support. HNTs were imaged after their dehydration. Images were analyzed by Nanoscope software (version 7.30s1rs2) and by SXM image (v.188, by Steve Barrett, England) (Figure 3A). Figure 3C has been processed by WSXM (20).

Confocal Laser Scanning Fluorescence Microscopy. Confocal micrographs were taken with a confocal scanning system Leica TCS SP5 (Leica Microsystem GmbH, Mannheim, Germany) and equipped with a $63 \times$ oil immersion objective. $Z$ scan and $X Y$ scans images were acquired to demonstrate internalization of nanotubes into cells.

Cytotoxicity Analysis. MTT Assay. All cell lines described above were used in the general cytotoxicity test. The MTT system is measuring the activity of living cells via mitochondrial dehydrogenase activity. The halloysite suspensions at different concentration (from $1 \mu \mathrm{g} / \mathrm{mL}$ to $1 \mathrm{mg} / \mathrm{mL}$ ) were diluted with complete culture medium. The MTT method of cell determination is most effective when cultures are prepared in multiwell plates. HeLa and MCF-7 cells $\left(10^{5}\right.$ cells $\left./ \mathrm{mL}\right)$ were added to six-well culture plates at $2 \mathrm{~mL} /$ well and incubated with the nanotubes at $37{ }^{\circ} \mathrm{C}$ in $5 \% \mathrm{CO}_{2}, 95 \%$ relative humidity for 24 to 48 to $72 \mathrm{~h}$. The control was a complete culture medium. After an appropriate incubation period, cultures were removed from the incubator, and an MTT solution in the amount equal to $10 \%$ of the culture volume was aseptically added. Cultures were returned to incubator and incubated for $3 \mathrm{~h}$. After the incubation period, cultures were removed from the incubator, and resulting MTT formazane crystals were dissolved with acidified isopropanol solution at equal volume with culture. The plates were ready within $1 \mathrm{~h}$ after acidified isopropanol solution was added. After the incubation time, pipetting up and down was required to dissolve completely the MTT formazane crystals. An absorbance at wavelength of $570 \mathrm{~nm}$ was measured with Agilent 4853 UV-vis spectrophotometer. Subtract background absorbance was measured at $690 \mathrm{~nm}$. The viability percentage was expressed as the relative growth rate (RGR) by equation

$$
\mathrm{RGR}=\left(D_{\text {sample }} / D_{\text {control }}\right) 100 \%
$$

where $D_{\text {sample }}$ and $D_{\text {control }}$ are the absorbances of the sample and the negative control.

Trypan Blue Assay. Trypan Blue is one of the dye exclusion procedures for viable cell counting. This method is based on the principle that live (viable) cells do not take up certain dyes, whereas dead (nonviable) cells do. Live cells with intact cell membranes are not colored. Because cells are very selective in the compounds that pass through the membrane, in a viable cell, Trypan blue is not absorbed; however, it traverses the membrane in a dead cell. Therefore, dead cells are shown to be a distinctive blue color under a microscope, and living cells are excluded from staining. For the trypan blue assay, HeLa and MCF-7 cells $\left(10^{5}\right.$ cells $\left./ \mathrm{mL}\right)$ were added to six-well culture plates at $2 \mathrm{~mL} /$ well and incubated at $37{ }^{\circ} \mathrm{C}$ in $5 \% \mathrm{CO}_{2}, 95 \%$ relative humidity for 24 to 48 to $72 \mathrm{~h}$ with the nanotubes suspension. The halloysite suspension at different concentration (from $1 \mu \mathrm{g} / \mathrm{mL}$ to 1 $\mathrm{mg} / \mathrm{mL}$ ) was diluted with complete culture medium, which is used as control. After the appropriate incubation period, the medium of each well was collected. After trypsinization, the cells were collected and centrifuged. The pellet was resuspended in an appropriate amount of medium. The collected cells were mixed with the same volume of $0.4 \%$ trypan blue solution. Cells were allowed to stand from 5 to $15 \mathrm{~min}$. Later, $10 \mu \mathrm{L}$ of stained cells was placed in a hemocytometer, and the number of viable (unstained) and dead (stained) cells was counted with a light microscope. The viability percentage was expressed using the following equation: cell viability $(\%)=$ total viable cells (unstained)/ total cells (stained and unstained) $\times 100$. 


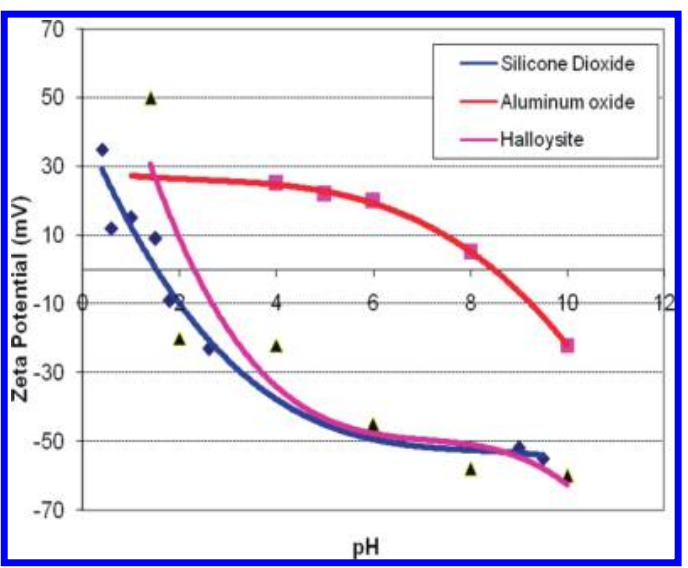

Figure 1. Comparison of $\xi$-potential curves for halloysite nanotubes (violet), silica (blue), and alumina (red) nanoparticles.

Nanotubes Uptake by Cells. Qualitative Study. To determine the cellular uptake of the nanotubes, we seeded $10^{5}$ cells $/ \mathrm{mL}$ in sterile glassculture slide coated with poly-L-lysine. The cells were incubated with the coated-nanotube dispersions. After $3 \mathrm{~h}$ of incubation at $37{ }^{\circ} \mathrm{C}$, the culture medium was removed, and cells were washed three times with phosphate-buffered saline and fixed in formaldeyde 3.7\%. After that, cells were stained with phalloidin and hoechst and processed by confocal microscopy.

\section{Results}

Characterization of Halloysite Nanotubes. HNTs form stable colloids in water in wide $\mathrm{pH}$ range. Figure 1 shows that halloysite is negatively charged above $\mathrm{pH} 2.4$ with $\xi$-potential reaching $-50 \mathrm{mV}$ at $\mathrm{pH} 6$ and higher. High $\zeta$-potential is a condition of good colloidal stability of dispersed nanotubes. An interesting feature is that because of different outside and inside chemistry (which comprise silica, $\mathrm{SiO}_{2}$, and alumina, $\mathrm{Al}_{2} \mathrm{O}_{3}$, sheets, correspondingly) the tube lumen is charged positively, whereas the external surface is charged negatively. This property of the tubes allows loading of negative molecules selectively into the lumen at the range of $\mathrm{pH}$ from 2.5 to 8.5 . In the same Figure 1, for comparison, we present the $\zeta$-potential of silica and alumina demonstrating this "window" of oppositely charged internal and external surfaces.

Figure 2 shows electron microscopy images, SEM (a) and TEM $(b-d)$, obtained from halloysite spread on flat support (a,c) and obtained from halloysite embedded into PMMA (b,d). One can see that the majority of the sample consists of cylindrical tubes of 40-50 nm diameter and length of 0.5 to 2 $\mu \mathrm{m}$. HNTs are rather polydisperse in length. TEM images clearly indicate the empty lumen of the halloysite with $15-20 \mathrm{~nm}$ diameters. For some tubes, one can see loose packing of the outermost alumosilicate sheets, which are not tightly rolled (Figure 2c).

SFM images (Figure 3) reveal the surface morphology of the tubes demonstrating the rolled nature of the tubes. SFM micrographs are acquired both in tapping mode (Figure 3a) and in contact mode (Figure 3b). Figure $3 b$ shows a deflection (error signal mode) contact mode SFM image of two isolated tubes, enhancing morphological details. Halloysite particles appeared to be rolled cylindrically, as shown in the $3 \mathrm{D}$ view of a long isolated tube. The tube diameter measured from SFM is ca. 100 $\mathrm{nm}$ (see inset in Figure 3b), which is larger than the one measured from TEM images. It may be related to SFM tip size (which has a radius of curvature of around $20 \mathrm{~nm}$ ) convolution. Another reason for larger SFM diameter may be the presence

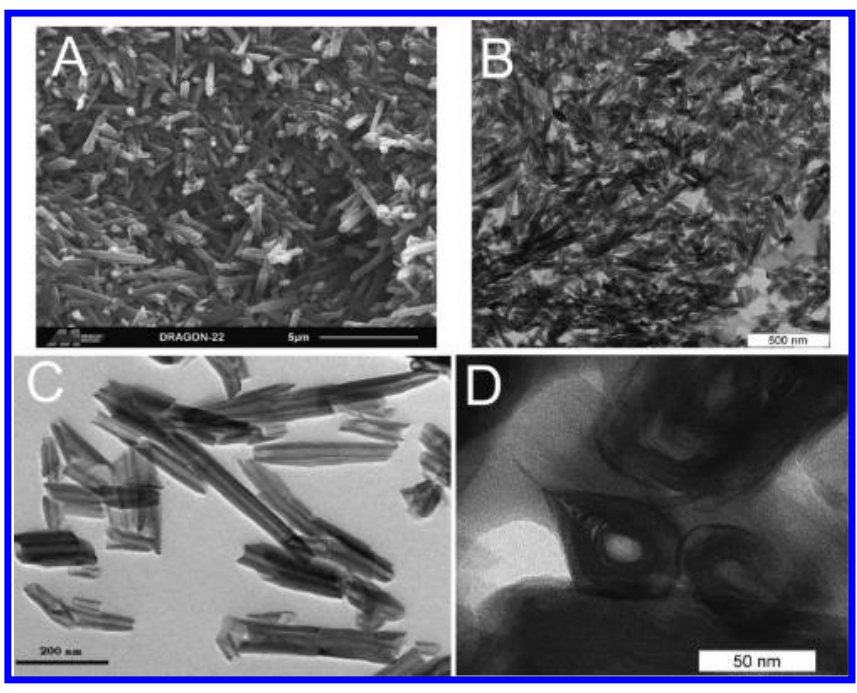

Figure 2. (a) SEM image of halloysite nanotubes powder, as supplied from Dragon Mine, Applied Minerals, Inc. TEM images of halloysite clay nanotubes: $(b, c)$ longitude and (d) cross-section.

of external loosely packed aluminosilicate layers that are not well resolved in TEM image because they are only 1 to $2 \mathrm{~nm}$ thick but may be detected with SFM. An additional argument for this could be the very small value of elasticity modulus measured (ca. $200 \mathrm{kPa}$ ). HNT elasticity is considerably smaller than that of carbon nanotubes (CNTs), which usually have a Young's modulus of $\sim 1 \mathrm{TPa}^{20,21}$ Such large differences in elastic properties between CNTs and HNTs could facilitate HNT internalization into cellular compartments, enhancing spontaneous penetration.

Imaging Halloysite Nanotubes Uptaken by the Cells. To study halloysite cytotoxicity, we added these clay nanotubes (both fluorescently labeled and unlabeled) to two model cell cultures (MCF-7 (breast cancer) and HeLa (cervical cancer) cells). Figures 4 and 5 demonstrate halloysite uptake by cells. In Figure 4, two orthogonal $X Z$ sections of a $Z$-stack for MCF-7 and $\mathrm{HeLa}$ are shown. In the bottom and right sides of the Figure 4A, the MCF-7 cell cytoskeleton (red, TRITC-labeled) with colocalized HNTs of yellow color, merging from FITC-labeled HNTs (green) and phalloidin-TRITC-labeled cytoskeleton (red) are shown. Similarly, in the bottom and right sides of the Figure 4B the localization of HNTs (green) outside HeLa nuclei (blue, Hoechst staining) is illustrated. HNTs accumulate all over the cell colonies (yellow coverage over red cytoskeleton). These images demonstrate effective internalization of HNTs in the cells.

In Figure 5, we report confocal micrographs of MCF-7 $(\mathrm{a}-\mathrm{c})$ and $\mathrm{HeLa}(\mathrm{d}-\mathrm{f})$ cells interacting with HNTs (fluorescent-labeled either by LBL or by APTES) showing colocalization of HNTs aggregates (green) around cell nuclei (blue). One can see that in both cases, labeled halloysite readily penetrates the cells (green area around blue cell nuclei). LbL-coated HNTs containing FITC-labeled layer (green) were analyzed for breast cancer cells, MCF-7. APTES-FITC-processed halloysite gives brighter images, indicating better FITC labeling. LbL polyelectrolyte multilayer coating had lower image sensitivity as compared with tube labeling through APTES-FITC. HNTs are readily uptaken by cells, predominantly in the cytoplasmatic region (outside nuclear regions, blue). A similar result was obtained for APTESfunctionalized HNTs (green), but HeLa cells were used in this case instead of MCF-7 (Figure 5e,f).

Halloysite Cytotoxicity. Uncoated Halloysite. Figures 6 and 8 summarize data on cytotoxicity of halloysite studied with 


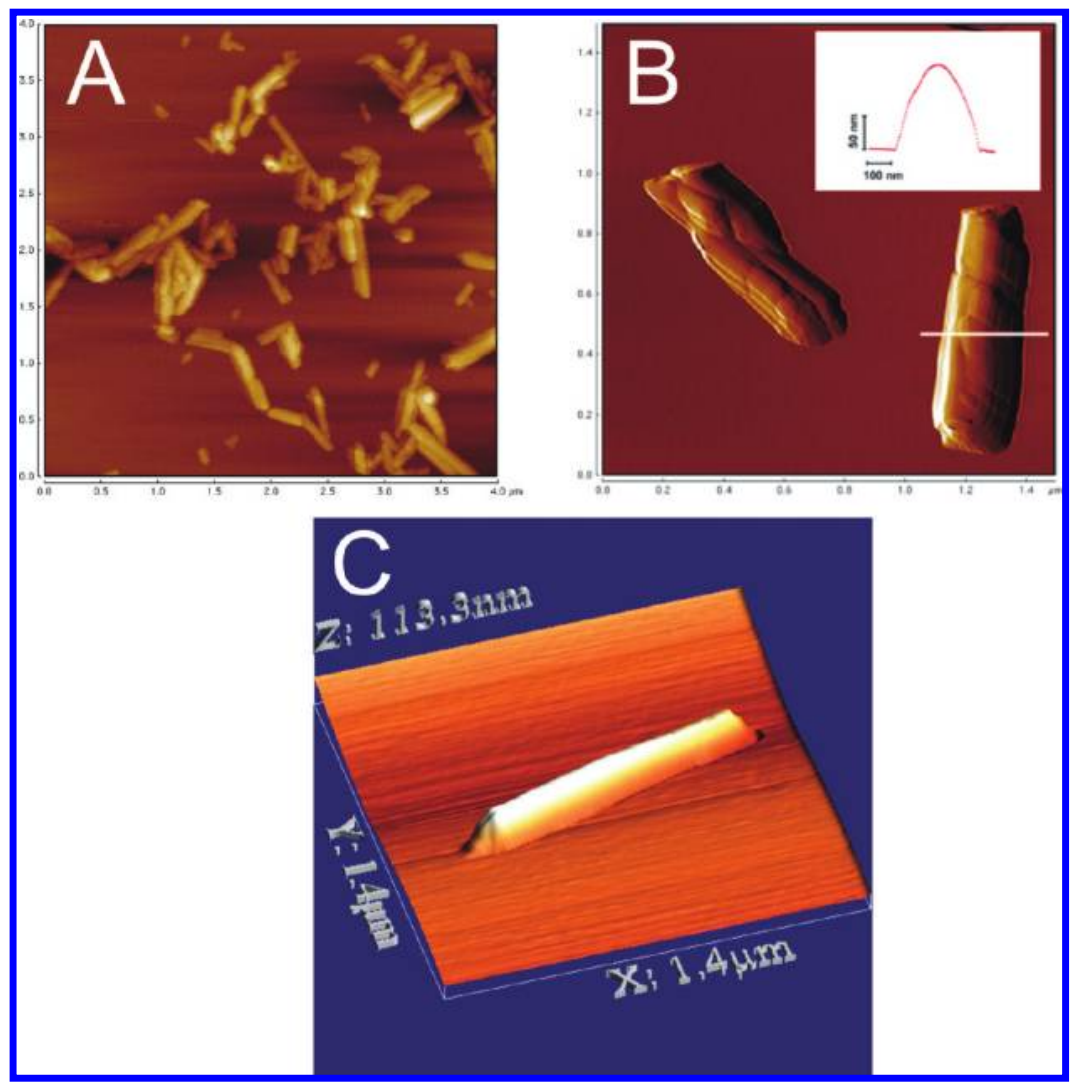

Figure 3. (a) Tapping mode SFM image of halloysite clay nanotubes ( $Z$ scale $700 \mathrm{~nm}$ ). (b) Contact mode (deflection) image of two isolated nanotubes. A typical height profile of a single nanotube is shown in the inset. (c) 3D view of a single long nanotube.

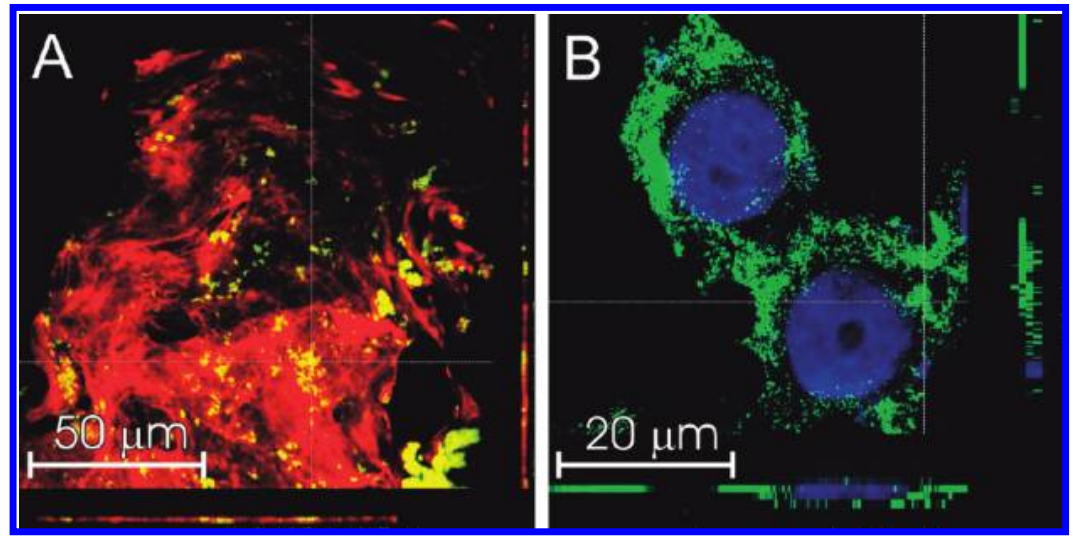

Figure 4. (a) CLSM image of halloysite nanotubes (HNTs) intracellular uptake by MCF-7 cells. Sections of a Z-stack FITC fluorescence (green) and phallloidin-TRITC fluorescence overlaid images (image size: $108 \mathrm{~mm}$ ). (b) CLSM image of HNTs (functionalized by APTES) intracellular uptake by HeLa cells. Sections of a Z-stack FITC fluorescence of HNTs+APTES (green) and Hoechst-fluorescence-stained HeLa nuclei (blue) overlaid images (image size: $42 \mathrm{~mm}$ ).

human cell models: breast cancer cell line (MCF-7) and cervical cancer cell (HeLa). We performed MTT tests at different time intervals ( 24 to 48 to $72 \mathrm{~h}$ ) and at different concentrations (from $1 \mu \mathrm{g} / \mathrm{mL}$ to $1 \mathrm{mg} / \mathrm{mL}$ ). The powder of halloysite was dispersed in DI water and added to the cell cultures. In both cell lines, the HNTs exhibited growth inhibition in a concentrationdependent manner. The cell viability was preserved (ca. 70\% of cells survived) up to halloysite concentration of $75 \mu \mathrm{g} / \mathrm{mL}$ (Figure 6 and 8). With increasing tube concentration up to 1000 $\mu \mathrm{g} / \mathrm{mL}$, there is a clear decrease in cell vitality (less pronounced for longer incubation time). For MCF-7 cells, mortality was increasing for the same concentration range as for Hela cells.

FITC-Labeled Halloysite. To follow halloysite localization into the cells and to study its uptake, we used nanotubes functionalized with FITC, as described above. Figure 7 gives the toxicity of APTES-FITC-functionalized HNTs for two cell lines. HeLa and MCF-7 cell mortality increases with increasing concentration for both cells in a similar manner with uncoated nanotubes.

Therefore, uncoated and APTES-functionalized HNTs did not the effect cell viability, and the trends in the cell viability were the same. These toxicity data were also confirmed by Trypan blue tests performed under the same conditions as those for nonfunctionalized nanotubes (Figure 8). These data show that nanotubes were uptaken by cells, and their viability is maintained at $>70 \%$ for HNT concentrations up to $75 \mu \mathrm{g} / \mathrm{mL}$, suggesting high biocompatibility of halloysite. With increasing halloysite concentration, there is a significant vitality reduction (Figure 8A,B). 


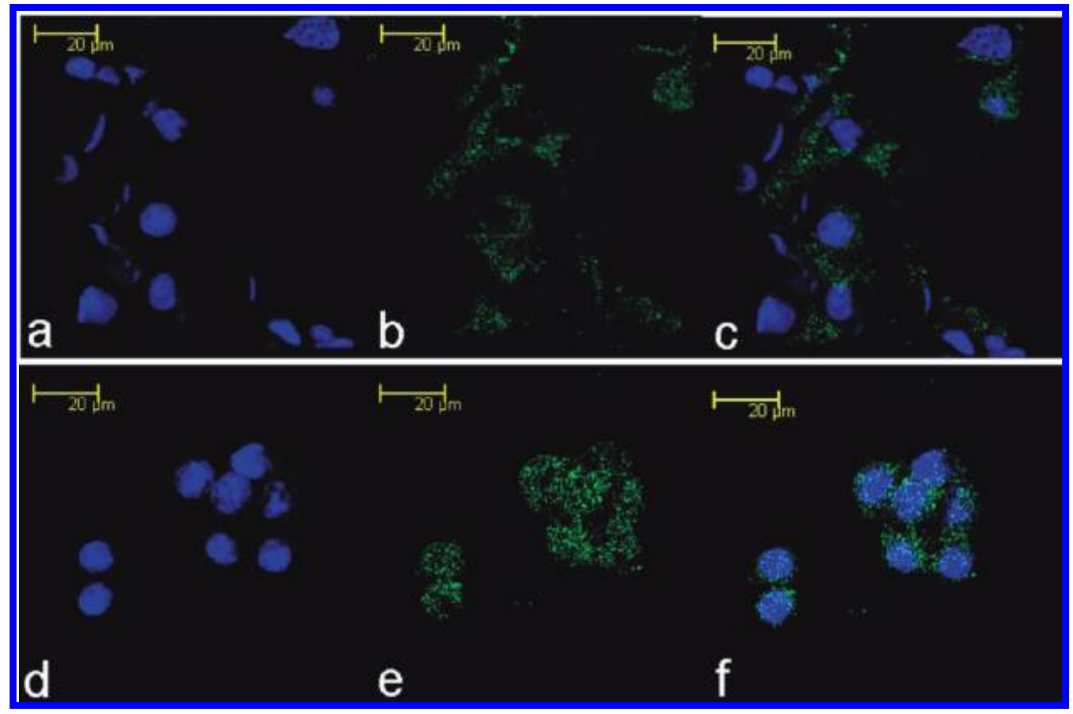

Figure 5. CLSM images of halloysite nanotubes (HNTs) intracellular uptake by cancer cells. (a-c) CLSM images of HNT (coated by polyelectrolyte multilayers with a FITC-labeled layer embedded herein) spontaneous intracellular uptake by MCF-7 cells. (a) Hoechst fluorescence of nuclei (blue). (b) FITC fluorescence (green) of HNTs coated with an FITC layer embedded in polyelectrolyte multilayers. (c) FITC fluorescence of HNTs with a FITC layer and MCF-7 nuclei (blue) overlaid images. (d,e) CLSM images of HNT (functionalized by APTES) spontaneous intracellular uptake by HeLa cells. (d) Hoechst fluorescence of nuclei (blue). (e) FITC fluorescence (green) of HNTs+APTES. (f) FITC fluorescence of HNTs+APTES and HeLa nuclei (blue) overlaid images.



Figure 6. MTT assay of halloysite taken up by (a) HeLa and (b) MCF-7 cell percent cell viability versus halloysite concentration for 24 to 48 to $72 \mathrm{~h}$ (Error bar is STD (standard deviation), not visible).

\section{Discussion}

Biocompatibility experiments were previously performed on halloysite multilayer assembled on plastic or glass surface via LbL process via alternated adsorption with cationic poly(ethyleneimine) or poly(lysine). ${ }^{10}$ Hydrogel formation through interaction between clay and polyelectrolytes was also reported. ${ }^{11}$ This implies that claylike materials may have high affinity to water in the presence of counter-charged materials.

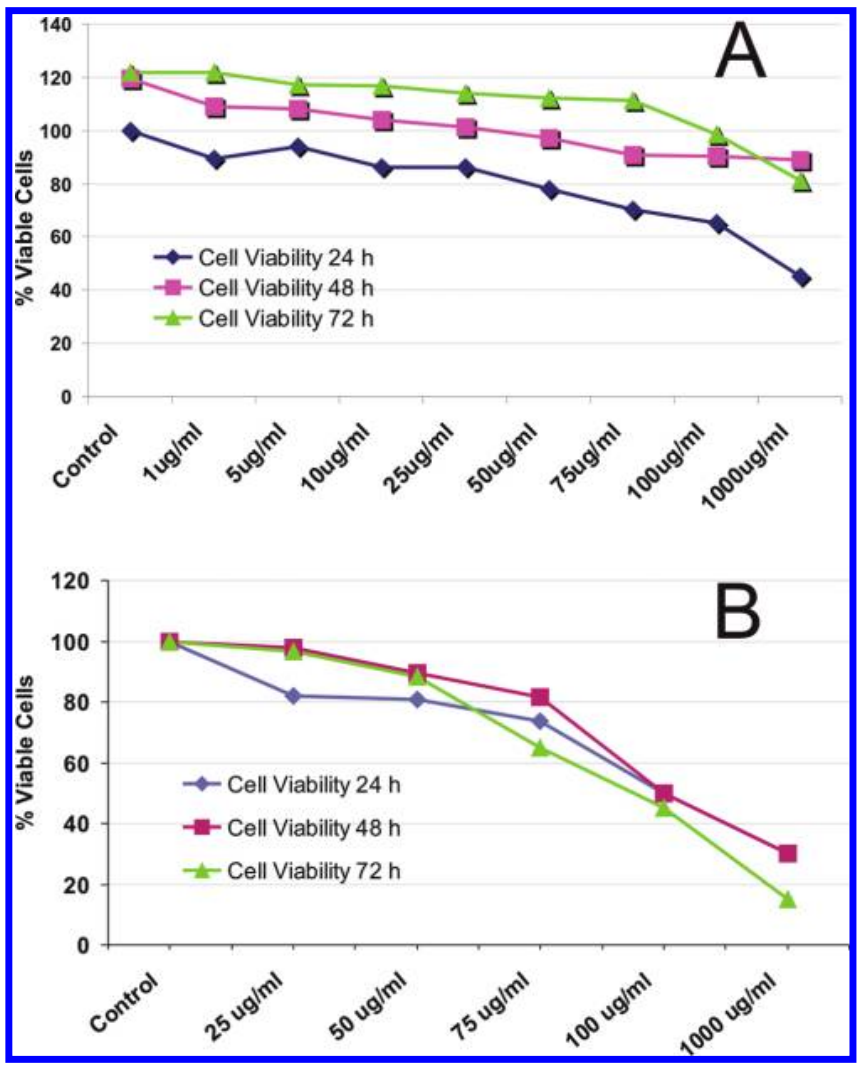

Figure 7. MTT assay of halloysite nanotubes (HNTs) functionalized with APTES on (a) HeLa (cervical cancer) and (b) MCF-7 cells. Percent cell viability versus HNTs+APTES concentration for 24 to 48 to 72 h. (Error bar is STD (standard deviation), not visible).

Similarly, halloysite may be highly hydrated under biological conditions, which may result in high-level biocompatibility. Very thin halloysite multilayer (ca. $300 \mathrm{~nm}$ ) improved adhesion of human dermal fibroblasts, and fibroblasts maintained their cellular phenoptype on this coating. Fibroblast cell attachment and spreading was faster on halloysite-coated substrate as compared with silica and montmorillonite clay coating or bare 


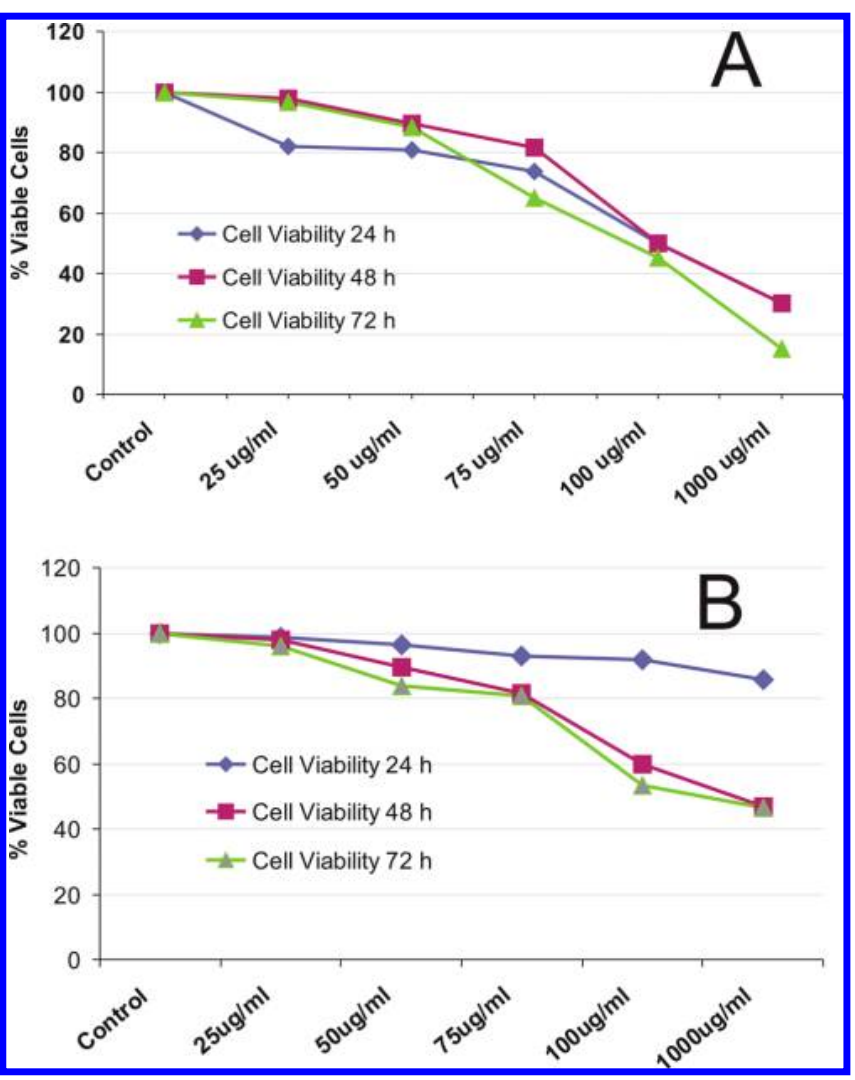

Figure 8. Trypan Blue test of halloysite nanotubes in (a) MCF-7 and (b) HeLa Cells. Percent cell viability versus halloysite concentration for 24 to 48 to $72 \mathrm{~h}$.

glass. ${ }^{10}$ Later, similar results endorisng osteoblast and fibroblasts cell proliferation were obtained for composites of poly(vynil alcohol) containing up to $5 \mathrm{wt} \%$ of halloysite. ${ }^{14}$ In all of these tests, biological cells were seeded on halloysite-containing surfaces, and no data on HNTs penetration into cells were provided.

More halloysite exposure to biological tissue is expected if one applies HNTs for drug delivery or medical implants (such as tooth fillers or bone cements). ${ }^{3-5,9,10}$ For example, in the case of bone implants with typical size of ca. $1 \mathrm{~cm}^{2}$ of polymetmethacrylate-based cement loaded with 3 wt \% of halloysite, it contains ca. $10^{10}$ clay nanotubes in the $10 \mu \mathrm{m}$ surface layer. Eventually, during a months-long degradation process, these clay nanoparticles may be released to connected biological tissue having mass of a few grams. Still, this concentration of ca. $1 \mu \mathrm{g} / \mathrm{mL}$ is at least 100 times less than given above data on safe halloysite concentration. In ref 8 , we tested the toxicity of halloysite for 24 to $48 \mathrm{~h}$ of incubation time for fibroblasts and human breast cells. It was observed that halloysite is nontoxic to these cells and is even much less harmful than usual salt $(\mathrm{NaCl})$. The percentage of live cells, as determined by celltiter-96 reagent, was measured for various concentrations of testing agents (raw halloysite was added to 0.1 to $100 \mu \mathrm{g} / \mathrm{mL}$ of culture, and sodium chloride was a negative control).

Our data show that the addition of even as much as 75 $\mu \mathrm{g} / \mathrm{mL}$ of halloysite in cell culture did not kill tested cells. (For comparison, the addition of only $50 \mu \mathrm{g} / \mathrm{mL}$ of usual $\mathrm{NaCl}$ killed all the cells.) Fluorescence confocal microscopy data revealed that the cells accumulate halloysite in their interior, but this does not prevent their proliferation. We were able to visualize the process of cellular uptake and have shown that HNTs penetrate into the cells and concentrate around the cell nuclea. Of course, testing with other cells as well as small animals will proceed to be driven by these clay nanotube application perspectives.

Studying halloysite toxicity, we had in mind blick data on asbestos toxicity and its danger for living organisms. ${ }^{21,22}$ The main difference of halloysite, as compared with asbestos microfibers, is that these nanotubes are much shorter and thinner and fit the size window $(0.5-1.5 \mu \mathrm{m})$, which is generally considered to be not toxic for silicate nanoparticles. ${ }^{24}$ Halloysite is just a rolled version of widely-adopted-in-human-life kaolin clay (alumosilicate) and is chemically different from asbestos, which is magnesium silicate (chrysolite), or less common $\mathrm{Na}$ and $\mathrm{Fe}, \mathrm{Mg}$ silicates (amphiboles). The danger of asbestos is based on its very long fiber structure (5-20 $\mu \mathrm{m}$ length). In the review on mechanisms of asbestos pathogenesis, ${ }^{23}$ it is indicated that asbestos fibers shorter than $5 \mu \mathrm{m}$ are safer. Long thin fibers are more potent inducers of cell injury and inflammation. Halloysite tube length of ca. $1 \mu \mathrm{m}$ allows their easier removal by macrophages.

Another point is the concentration range: in our experiments, halloysite concentration up to $75 \mu \mathrm{g} / \mathrm{mL}$ (ca. $10^{11}$ particles per gram of cells) was safe for the cells, whereas asbestos disease is caused by a much smaller number of asbestos fibers per gram of lung (ca. $10^{8}$ particle per gram). Therefore, already 1000 times less particle concentration of asbestos as compared with halloysite causes a disease.

Generally speaking, cytotoxicity of asbestos fibers is much higher as compared with that of other minerals. Hart and Hesterberg ${ }^{23}$ carried out studies showing moderate cytotoxic effect of different silica-rich minerals as compared with asbestos. There is a little inconsistency with different literature sources as to what the threshold is for silica particle size for cytotoxic or fibrogenic effects, but in all publications, particles larger than $5 \mu \mathrm{m}$ were found to be more fibrogenic than particles of $1 \mu \mathrm{m}$ in diameter or less. ${ }^{22-24}$ Toxicity of halloysite may be compared with that of silica nanoparticles because its external surface exposed to intracellular media is silica. Our results have shown that even large amounts of added halloysite (up to $75 \mu \mathrm{g} / \mathrm{mL}$ ) did not show toxicity, and at least $90 \%$ of the cells survived, whereas from the fluorescence laser confocal images, one could see that nanotubes were taken up by the cells. From our point of view, direct toxicity of halloysite to cells will not be the issue in applications, oppositely, for example, to CNTs, which kill cells. ${ }^{25,26}$ Polyelectrolyte nanotubes assembled in alumina cylindrical pores could be another reference for our work. ${ }^{27}$ These tubes have dimensions close to those of the HNTs and also have low toxicity and were readily internalized into cancer cells.

Secondary effects of HNTs on tissue may be essential, such as increased fibrogenicity, but it is not always harmful and may be even useful, for example, for bone implants. As the collective research stands, experimentation with macrophage exposure to halloysite seems appropriate and ultimately inevitable at the next research step.

\section{Conclusions}

With TEM, SEM, and SFM microscopy, we characterized halloysite clay as tubular nanoparticles of ca. $50 \mathrm{~nm}$ external diameter, $15 \mathrm{~nm}$ lumen diameter, and of 500-1500 nm length. In wide range of $\mathrm{pH}$, it has negative electrical $\zeta$-potential of ca. $-50 \mathrm{mV}$, which allows halloysite good dispersibility and colloidal stability in water. An addition of halloysite to two different cell lines demonstrated that it is nontoxic up to 
concentrations of $75 \mu \mathrm{g} / \mathrm{mL}$, whereas parallel laser confocal visualization of cell uptake of fluorescently labeled halloysite demonstrated its location within the cells in the nuclear vicinity. The current research suggests that HNTs are not toxic for cells.

Acknowledgment. Financial support of Italian Ministry of University and Research (MIUR) through FIRB project no. RBLA03ER38 is gratefully acknowledged. " Con il contributo del Ministero degli Affari Esteri, Direzione Generale per la promozione e la Cooperazione Sociale " (Italy-USA Bilateral Project "Nano-Carriers for Cancer Therapy"). We acknowledge Applied Minerals, Inc. for providing halloysite and David Mills (Louisiana Tech University) for data concerning halloysite bone implants. Support by Louisiana Board of Regent grant LEQSF2009RD is acknowledged.

\section{References and Notes}

(1) Joussein, E.; Petit, S.; Churchman, J.; Theng, B.; Righi, D.; Delvaux, B. Halloysite Clay Minerals: A Review. Clav Minerals 2005, 40, $383-$ 426.

(2) Tari, G.; Bobos, I.; Gomes, C.; Ferreira, J. Modification of Surface Charge Properties During Kaolinate to Halloysite-7A Transformation. J. Colloid Interface Sci. 1999, 210, 360-369.

(3) Price, R.; Gaber, B.; Lvov, Y. Release Characteristics of Tetracycline, Khellin and NAD from Halloysite: A Cylindrical Mineral for Delivery of Biologically Active Agents. J. Microencapsulation 2001, 18, 713 723 .

(4) Shchukin, D.; Price, R.; Sukhorukov, G.; Lvov, Y. Biomimetic Synthesis of Vaterite in the Interior of Clay Nanotubules. Small 2005, $1,510-513$

(5) Kelly, H.; Deasy, P.; Ziaka, E.; Claffey, N. Formulation and Preliminary in Vivo Dog Studies of a Novel Drug Delivery System for the Treatment of Periodontitis. Int. J. Pharm. 2004, 274, 167183.

(6) Veerabadran, N.; Price, R.; Lvov, Y. Clay Nanotubules for Drug Encapsulation and Sustained Release. NANO 2007, 2, 215-222.

(7) Lvov, Y.; Shchukin, D.; Mohwald, H.; Price, R. Clay Nanotubes for Controlled Release of Protective Agents. ACS Nano 2008, 2, 814 820.

(8) Abdullayev, E.; Price, R.; Shchukin, D.; Lvov, Y. Halloysite Tubes as Nanocontainers for Anticorrosion Coating with Benzotriazole. $\underline{A C S}$ Appl. Mater. Interfaces 2009, 2, 1437-1443.

(9) Veerabadran, N.; Mongayt, D.; Torchilin, V.; Price, R.; Lvov, Y. Organized Shells on Clay Nanotubes for Controlled Release of Macromolecules. Macromol. Rapid Commun. 2009, 30, 94-9.

(10) Kommireddy, D.; Ichinose, I.; Lvov, Y.; Mills, D. Nanoparticle Multilayer: Surface Modification for Cell Attachment and Growth. J. Biomed. Nanotechnol. 2005, 1, 286-290.

(11) Lvov, Y.; Ariga, K.; Ichinose, I.; Kunitake, T. Formation of Ultrathin Multilayer and Hydrated Gel from Montmorillonite and Linear Polycations. Langmuir 1996, 12, 3038-3044.
(12) Viseras, M. T.; Aguzzi, C.; Cerezo, P.; Cultrone, G.; Viseras, C. Supramolecular Structure of 5-Aminosalycilic Acid/Halloysite Composites. J. Microencapsulation 2009, 26, 279-286.

(13) Liu, M.; Guo, B.; Zou, Q.; Du, M.; Jia, D. Interaction between Halloysite Nanotubes and 2,5-Bis(2-benzoxazolyl) Thiophene and Their Effect on Reinforcement of Polypropylene Nanocomposites. Nanotechnology 2008, 19, 205709.

(14) Zhou, W.; Guo, B.; Liu, M.; Liao, R.; Rabie, A.; Jia, D. Poly(vinyl alcohol)/Halloysite Nanotubes Bionanocomposite Films. J. Biomed. Mater. Res., Part A 2009, 2, 1456-1463.

(15) Yuan, P.; Southon, P.; Liu, Z.; Green, M.; Hook, J.; Antill, S.; Kepert, C. Functionalization of Halloysite Clay Nanotubes by Grafting with Aminopropyltriethosilane. J. Phvs. Chem. C 2008, 112, 15742-15751.

(16) Liu, P.; Zhao, M. Silver Nanoparticle Supported on Halloysite Nanotubes Catalyzed Reduction of 4-Nitrophenol. Appl. Surf. Sci. 2009, 255, 3989-3993.

(17) Sukhorukov, G.; Donath, E.; Davis, S.; Lichtenfeld, H.; Caruso, F.; Popov, V.; Möhwald, H. Stepwise Polyelectrolyte Assembly on Particle Surface: A Novel Approach to Colloid Design. Polvm. Adv. Technol. 1998, 9, 759-767.

(18) Leporatti, S.; Voigt, A.; Mitlöhner, R.; Sukhorukov, G.; Donath, E.; Möhwald, H. Scanning Force Microscopy Investigation of Polyelectrolyte Nano- and Microcapsule Wall Texture. Langmuir 2000, 16, 8850-8857.

(19) Javier, A. M.; Kreft, O.; Semmling, M.; Kempter, S.; Skirtach, A. G.; Bruns, O. T.; del Pino, P.; Bedard, M. F.; Rädler, J.; Käs, J.; Plank, C.; Sukhorukov, G. B.; Parak, W. J. Uptake of Colloidal Polyelectrolyte-Coated Particles. Adv. Mater. 2008, 20, 4281-4290.

(20) Horcas, I.; Fernandez, R.; Gomez-Rodriguez, J.; Colchero, J.; GomezHerrero, J.; Baro, A. M. WSxM: A Software for Scanning Probe Microscopy and a Tool for Nanotechnology. Rev. Sci. Instrum. 2007, $78,13705$.

(21) Treacy, M.; Ebbesen, T.; Gibson, J. Exceptionally High Young's Modulus Observed for Individual Carbon Nanotubes. Nature 1996, 381, 678-680.

(22) Mossman, B.; Churg, A. Mechanisms in the Pathogenesis of Asbestosis and Silicosis. Am. J. Respir. Crit. Care Med. 1998, 157, 1666-1680.

(23) Hart, G.; Hesterberg, T. In Vitro Toxicity of Respirable-Size Particles of Diatomaceous Earth and Crystalline Silica Compared with Asbestos and Titanium Dioxide. J. Occup. Environ. Med. 1998, 40, 29-42.

(24) Wiessner, J.; Mandel, N.; Sohnle, P.; Mandel, G. Effect of Particle Size on Quartz-induced Hemolysis and on Lung Inflammation and Fibrosis. Exp. Lung. Res. 1989, 15, 801-812.

(25) Porter, A.; Gass, M.; Muller, K.; Skepper, J.; Midgley, P.; Welland, M. Direct Imaging of Single-Walled Carbon Nanotubes in Cells. Nat. Mater. 2007, 2, 713-718.

(26) Nel, A.; Xia, T.; Madler, L.; Li, N. Toxic Potential of Materials at the Nanolevel. Science 2006, 311, 622-628.

(27) Yang, Y.; He, Q.; Duan, L.; Li, J. B. Assembled Alginate/Chitosan Nanotubes for Biological Application. Biomaterials 2007, 18, 3083-3090.

BM9014446 